\title{
Design and Analysis of a Frequency Reconfigurable Penta-Band Antenna for WLAN and 5G Applications
}

\author{
Rekha Shanmugam*
}

\begin{abstract}
This paper presents a discussion on a low-profile, frequency-reconfigurable penta-band antenna. This antenna consists of two asymmetric L-shaped rectangular patches electrically connected by a single PIN diode. The proposed antenna operates at five frequency bands depending upon the switching states of the PIN diode. It operates at $2.4 \mathrm{GHz}$ (WLAN) and $5.3 \mathrm{GHz}$ (5G) during forward bias of the diode, $3.3 \mathrm{GHz}(5 \mathrm{G})$ and $5.9 \mathrm{GHz}$ (WLAN) during reverse bias of the diode and $4 \mathrm{GHz}$ during zero bias condition providing a wide bandwidth $(3.6-4.8 \mathrm{GHz})$ at this state. The antenna has voltage standing wave ratio (VSWR) ranges from 1 to 2 , gain value ranges from 2.6 to $5.0 \mathrm{dBi}$, and a maximum radiation efficiency of $85 \%$. This antenna can be integrated with modern devices such as smart phones, laptops, and other handheld devices due to its simplistic geometry. A prototype of the model is fabricated, and the results are validated.
\end{abstract}

Key Words: Frequency Reconfigurability, PIN Diode, Rectangular Patch, WLAN, 5G Applications.

\section{INTRODUCTION}

Due to speedy developments in modern communication, there is a pressing need for reconfigurable antennas. Decades ago, individual antennas were employed to obtain different operating frequencies, increasing the dimensions of the system. Conversely, UWB antennas can be utilized to attain a wide frequency range $(3.1-10.6 \mathrm{GHz})$ [1]. However, there are some disadvantages in using UWB antennas, such as interference and co-existence with other radios. Thus, the concept of reconfigurability has evolved to avoid these scenarios. Frequency reconfigurability [2] has significantly reduced the antenna size, so that they can easily be employed in any compact handheld device. There are two other categories of reconfigurable antennas: polarization [3] and pattern [4]. It is possible to realize two or more reconfigurabilities at the same time depending on the number of switches. The cognitive radio system represents the near future of wireless communication, in which an antenna tunes to the desired frequency based on the available spectrum [5]. Accordingly, reconfigurable antennas are one of the best solutions for such adaptive systems and are used in satellite communications and radar systems.

Generally, reconfigurability is attained by using various switching devices, such as PIN diodes [6], varactor diodes [7], microelectromechanical systems (MEMS) switches [8], lumped elements [9], or optical switches [10]. These devices alter the structure (length) of the radiating element depending on the $\mathrm{ON}$ and $\mathrm{OFF}$ conditions. In the literature, many reconfigurable antennas have been designed that incorporate frequency, polarization, pattern, and hybrid reconfigurability (depending on the application). In [11], a PIN diode was included in the center of the slot, and frequency diversity was obtained by changing the

Manuscript received August 30, 2020 ; Revised December 23, 2020 ; Accepted March 2, 2021. (ID No. 20200830-131J)

Department of Electronics and Communication Engineering, Sreenidhi Institute of Science and Technology, Hyderabad, Telangana, India.

"Corresponding Author: Rekha Shanmugam (e-mail: mrs.s.rekha@gmail.com)

This is an Open-Access article distributed under the terms of the Creative Commons Attribution Non-Commercial License (http://creativecommons.org/licenses/by-nc/4.0) which permits unrestricted non-commercial use, distribution, and reproduction in any medium, provided the original work is properly cited.

(c) Copyright The Korean Institute of Electromagnetic Engineering and Science. 
bias voltage and keeping the other parameters (such as geometry and feeding probe) constant. The bandwidth can also be changed by varying the PIN diode. In [12], a ground plane was embedded with a DGS structure having two symmetrical Ushaped slots (with open ends) and an I-shaped slot (with a short end). The ground plane incorporated three PIN diodes to achieve multiband resonances.

In [13], a frequency reconfigurable antenna with coplanar waveguide $(\mathrm{CPW})$ feeding was designed to cover a wide frequency range $(2-10 \mathrm{GHz})$. The antenna used four PIN diodes to achieve different resonant frequencies in the wide frequency band. Further, the type of feeding, structure of the radiator, and number of diodes employed were the deciding factors for the operating frequency ranges. Discussions about a reconfigurable antenna having proximity couple feeding for WLAN and sub-6 $\mathrm{GHz}$ applications were presented in [14]. The antenna consisted of two substrates (separated by air) with four PIN diodes. However, the dimensions of the antenna are large and the structure is complex with this type of feeding. Finally, by using a reconfigurable feed network, frequency and polarization diversity can be achieved [15]. From the literature, it can be understood that PIN diodes are more user friendly in terms of less switching complexity, higher speed and reliability.

A compact, low-profile, frequency-reconfigurable microstrip patch antenna built on a FR4 substrate is discussed in this paper. Compared to conventional reconfigurable antenna models, this antenna only contains one PIN diode and generates five resonant frequencies. During forward bias, the operating bands are 2.4 and $5.3 \mathrm{GHz}$, whereas they are 3.3 and $5.9 \mathrm{GHz}$ in reverse bias. These operating frequencies cover the WLAN (2.4 and 5.9 $\mathrm{GHz})$ and $5 \mathrm{G}(5.3$ and $3.7 \mathrm{GHz})$ bands. During zero bias, the antenna operates between 3.6 and $4.8 \mathrm{GHz}$.

Section II presents a discussion about the antenna design, including the geometry, design equations, switching techniques, and current distribution. Section III focuses on the simulation and fabrication results, while Section IV provides a brief conclusion of the proposed work.

\section{ANTENNA DESIGN}

\section{Geometry of the Proposed Antenna}

The model consists of two asymmetric L-shaped rectangular patches, with one of the patches fed through a $50 \Omega$ microstrip line. The antenna was printed on a lossy FR4 substrate material -relative permittivity $\left(\boldsymbol{\varepsilon}_{\boldsymbol{r}}\right)$ of 4.4 and tangent loss $(\delta)$ of 0.02 with a thickness of $1.6 \mathrm{~mm}$. The use of FR4 was preferred in the proposed model because of its affordability and availability. The radiating element was backed by a metallic truncated ground plane to provide optimum efficiency, gain, and directivity. A rectangular stub was placed on the ground to improve imped- ance matching at higher resonant frequencies. An electrical path was provided between the two rectangular patches through a PIN diode. A full wave electromagnetic (EM) simulatorAnsys High Frequency Structure Simulator (HFSS)—was used to carry simulation of the proposed design. The total length of the radiator was $33.5 \mathrm{~mm}$, and the width was $4 \mathrm{~mm}$, and the overall dimensions was $40 \mathrm{~mm} \times 35 \mathrm{~mm} \times 1.6 \mathrm{~mm}$. The geometry of the antenna is shown in Fig. 1 . Table 1 presents the dimensions of the proposed model.

\section{Design Equations}

The effective length and dielectric permittivity of a rectangular radiating element are given by Eqs. (1) and (2) from [16].

$$
\begin{aligned}
& L_{e f f}=\frac{c}{4 f_{r \sqrt{\epsilon_{e f f}}}} \\
& \epsilon_{e f f} \approx \frac{\epsilon_{r}+1}{2}
\end{aligned}
$$

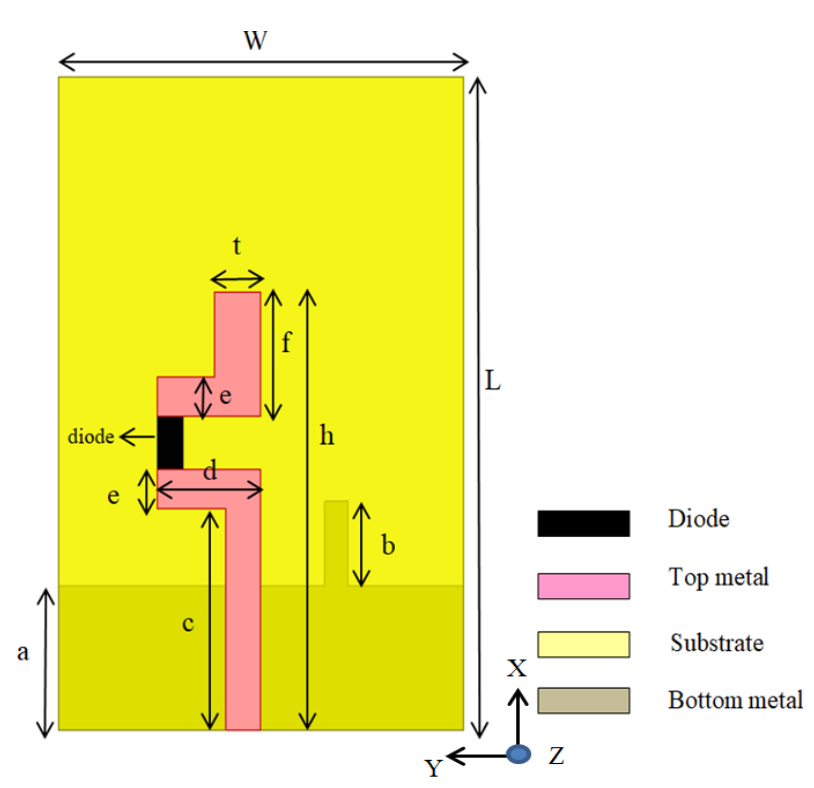

Fig. 1. Geometry of proposed model.

Table 1. Dimensions of proposed design

\begin{tabular}{ccc}
\hline S. No. & Dimension & Value $(\mathrm{mm})$ \\
\hline 1 & $L \times W$ & $40 \times 35$ \\
2 & $b$ & 33.5 \\
3 & $t$ & 4 \\
4 & $a$ & 11 \\
5 & $b$ & 6 \\
6 & $c$ & 17 \\
7 & $d$ & 9 \\
8 & $e$ & 3 \\
9 & $f$ & 9.5 \\
\hline
\end{tabular}


Here, $c$ is the velocity of light in free space, $f_{r}$ is the resonant frequency, $\epsilon_{\text {eff }}$ is the effective dielectric permittivity, $\epsilon_{r}$ is the permittivity of the dielectric substrate, $w$ is the width of the substrate, and $b$ is the height of the substrate.

If the antenna is excited at an appropriate impedance point, the reflection coefficient should be $<-10 \mathrm{~dB}$ and voltage standing wave ratio (VSWR) would range between 1 and 2 . The reflection coefficient is related to the impedance matching of the system and is given by Eq. (3).

$$
\text { Reflection coefficient }|\Gamma|=\frac{Z_{a}-Z_{f}}{Z_{a}+Z_{f}}
$$

Here, $\boldsymbol{Z}_{\boldsymbol{a}}$ is the impedance of the antenna, $\boldsymbol{Z}_{\boldsymbol{f}}$ is the feedline's characteristic impedance, and $\Gamma$ is the reflection coefficient. The VSWR is related to the reflection coefficient through Eq. (4).

$$
\operatorname{VSWR}=\frac{1+|\Gamma|}{1-|\Gamma|}
$$

\section{Switching Techniques}

A PIN diode (NXP BAP64-03, 100 mA, 20 V) was employed for frequency reconfiguration in the proposed model. The equivalent circuits of the PIN diode in its ON and OFF states are shown in Fig. 2(a) and (b), respectively.

The three biasing states of a PIN diode are as follows: (i) zero $\mathrm{DC}$, (ii) positive DC, and (iii) negative DC. In the simulation, the PIN diode was modelled as a lumped RLC equivalent. For zero DC bias, there was no connection between the two Lshaped rectangular patches (such that there was no electrical path between them). The lower L-shaped rectangular patch was the only active radiator. During positive DC bias, the diode represented a series combination of $2.5 \Omega$ resistance and 1.68 $\mathrm{nH}$ inductance (in the simulation). The lower value of $\mathrm{R}$ in the

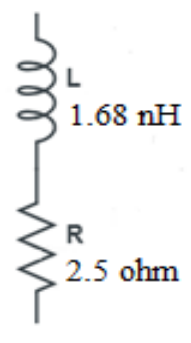

(a)

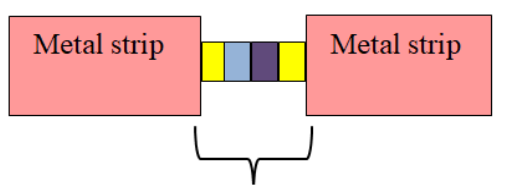

Lumped RLC boundary in HFSS (Equivalent to PIN diode model)

(c)

Fig. 2. Equivalent circuit of PIN diode in (a) ON, (b) OFF state, and (c) lumped RLC boundary in HFSS. forward bias increased the current flow between the radiating strips. During reverse DC bias, the diode provided a parallel combination of $0.3 \mathrm{pF}$ capacitance and $15 \mathrm{k} \Omega$ resistance in series with an inductance of $1.68 \mathrm{nH}$ (in the simulation). The higher value of $\mathrm{R}$ during reverse bias restricted the current flow.

The inductor value was kept constant, as it did not have any significant effect on the current distribution. The values of $R, L$, and $\mathrm{C}$ were considered from the data sheet of the PIN diode model. These values were tuned in the given range, ensuring resonance was achieved in the desired frequency band. The assignment of a lumped RLC boundary in the simulation tool, Ansys HFSS, is shown in Fig 2(c). Bias voltages of $0,+3$, and $-3 \mathrm{~V}$ were applied to the circuit for the zero, forward, and reverse biases, respectively. Depending on the type of biasing, different resonant frequencies were obtained from the single antenna model, as indicated in Table 2.

\section{Current Distribution}

The proposed frequency reconfigurable antenna was simulated using Ansys HFSS. The far field radiation was mainly due to the current on the radiator. The simulated surface current densities at all five frequency bands are presented in Fig. 3. During forward bias, the antenna resonated at two frequencies. At the lower resonance, the surface current density was large on the lower L-shaped patch, as indicated in Fig. 3(a). The length of the lower L-shaped patch was $20 \mathrm{~mm}$ (i.e., $\mathrm{c}=17+\mathrm{e} \mathrm{mm}$ ), in which most of the current was distributed in the lower part (i.e., $c=17 \mathrm{~mm}$ ). The approximate length of the quarter wave at 2.4 $\mathrm{GHz}$ was calculated as $17 \mathrm{~mm}$ using the design Eqs. (1) and (2). This is illustrated using the vector surface current distribution at 2.4 GHz (phase $0^{\circ}$ ) in Fig. 4.

As indicated in Fig. 3(b), the surface current was distributed on the upper and lower L-shaped strips. It can also be observed that the surface current was distributed strongly around the stub. The length of the stub was slightly less than the quarter wavelength at $5.3 \mathrm{GHz}$. This rectangular stub on the ground plane played a vital role in achieving impedance matching at higher frequencies.

To illustrate the influence of the stub for impedance matching, the simulated reflection coefficient is plotted in Fig. 5.

Table 2. Different configurations of PIN diodes with their simulated operating frequencies

\begin{tabular}{ccccc}
\hline & $\begin{array}{c}\text { DC bias } \\
(\mathrm{V})\end{array}$ & Biasing state & $\begin{array}{c}\text { Operating } \\
\text { freq. }(\mathrm{GHz})\end{array}$ & $\begin{array}{c}\text { Bandwidth } \\
(\mathrm{GHz})\end{array}$ \\
\hline Case 1 & 0 & Zero bias & 4 & $3.6-4.8$ \\
Case 2 & +3 & Forward bias & 2.4 & $2.1-2.5$ \\
& & & 5.3 & $5.0-5.6$ \\
Case 3 & -3 & Reverse bias & 3.3 & $2.8-3.6$ \\
& & & 5.9 & $5.5-6.1$ \\
\hline
\end{tabular}




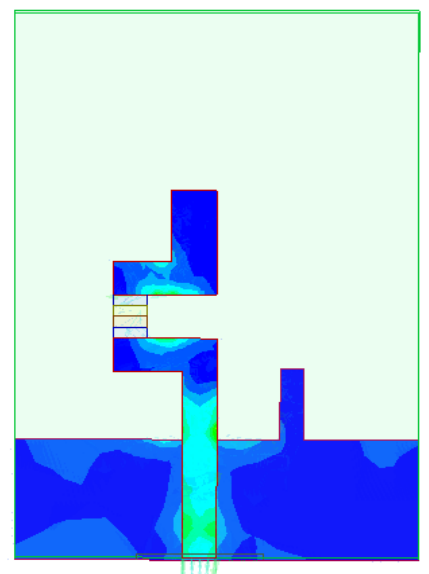

(a)

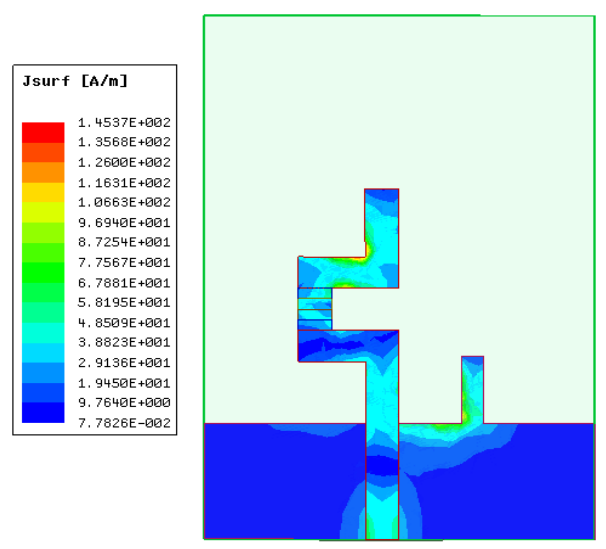

(d)

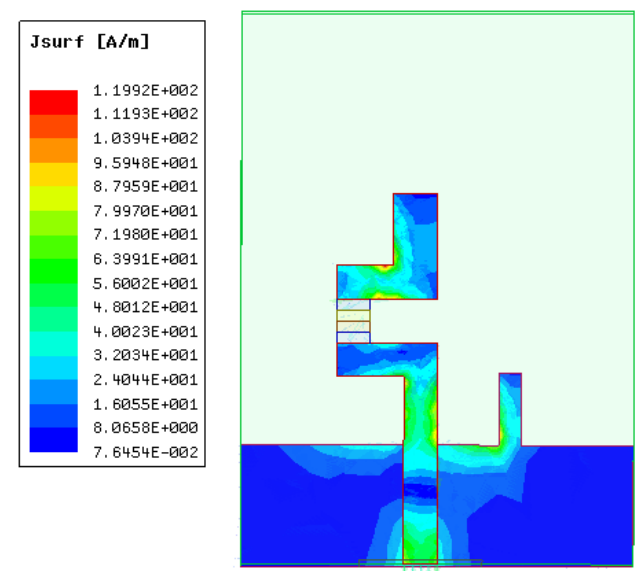

(b)

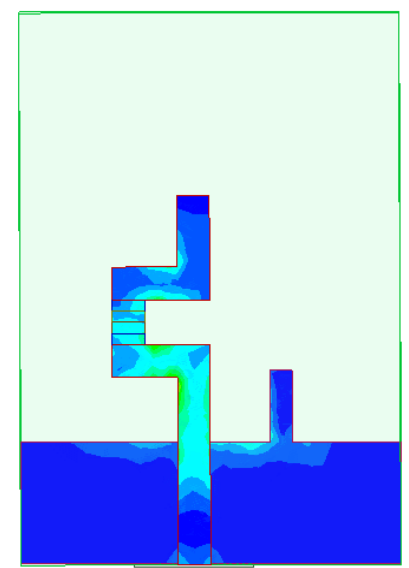

(c)

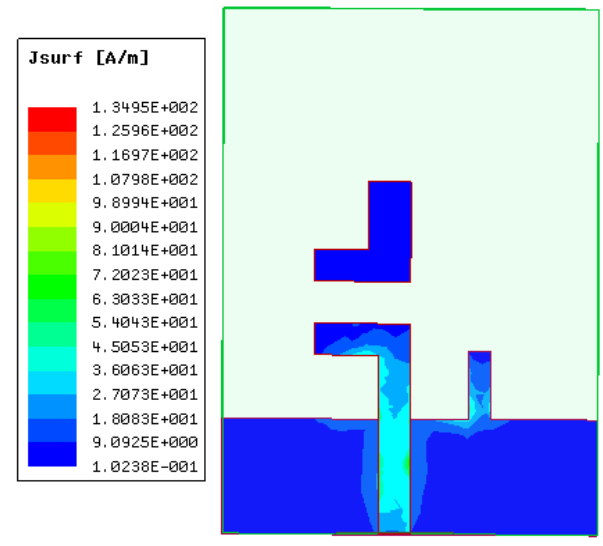

(e)

Fig. 3. Simulated surface current density of the proposed design at (a) $2.4 \mathrm{GHz}$, (b) $5.3 \mathrm{GHz}$, (c) $3.3 \mathrm{GHz}$, (d) $5.9 \mathrm{GHz}$, and (e) $4 \mathrm{GHz}$.

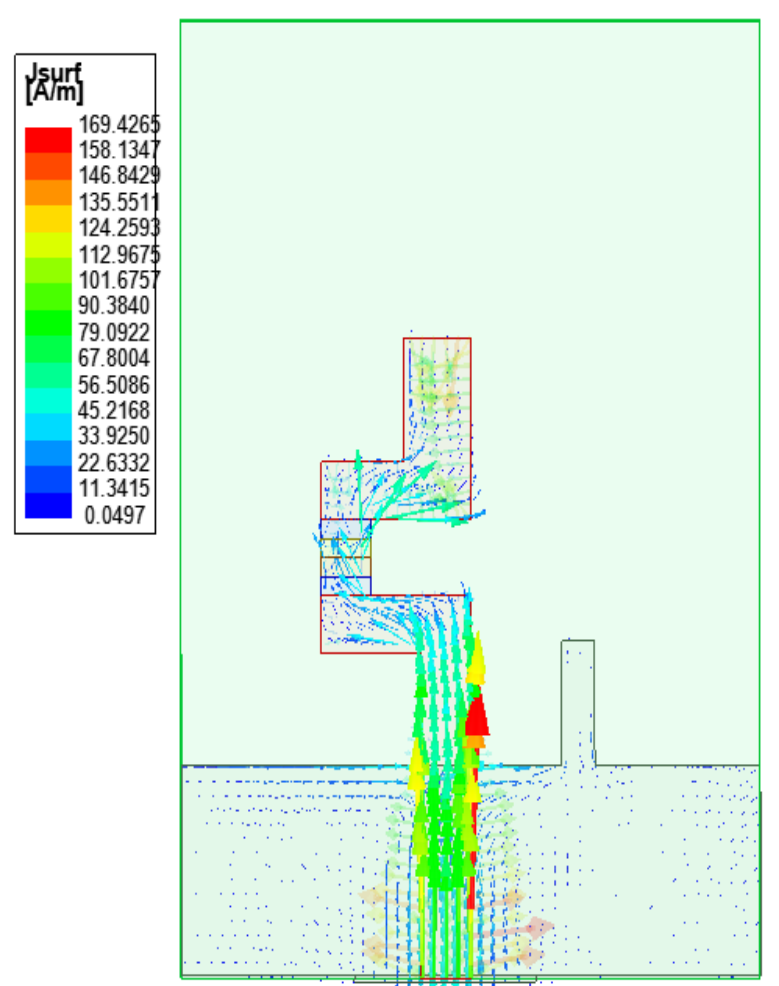

Fig. 4. Vector surface current distribution at $2.4 \mathrm{GHz}\left(\right.$ phase $\left.0^{\circ}\right)$.

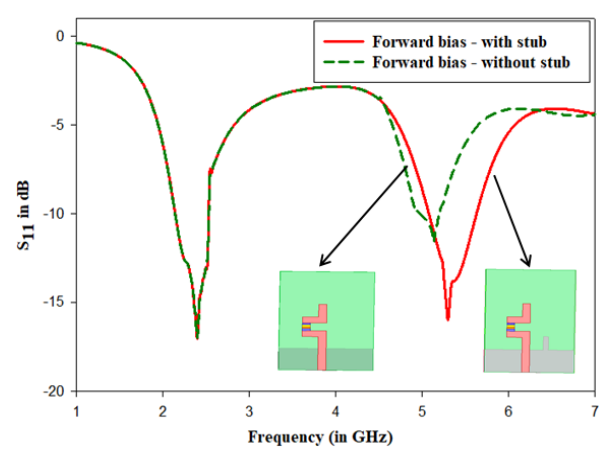

(a)

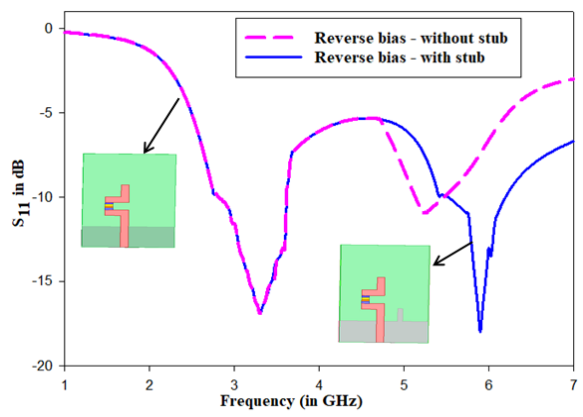

(b)

Fig. 5. Effects of stub at higher frequencies: (a) forward bias and (b) reverse bias. 
With the rectangular stub, the antenna realized improved matching at the higher frequencies: $5.3 \mathrm{GHz}$ in forward bias and $5.9 \mathrm{GHz}$ in reverse bias.

\section{RESULTS AND DISCUSSION}

To validate the results, the model was fabricated and then measured using an Agilent vector network analyzer. A photograph of the fabricated antenna is presented in Fig. 6, while Fig. 7 displays a comparison between the simulated and measured return losses. The simulated antenna (at zero bias) achieved a $-10 \mathrm{~dB}$ impedance bandwidth of $1.2 \mathrm{GHz}(3.6-4.8 \mathrm{GHz})$ with a center frequency at $4 \mathrm{GHz}$. During forward bias of the diode $(+3 \mathrm{~V})$, the antenna resonated at two frequencies: $2.4 \mathrm{GHz}$ $(2.1-2.5 \mathrm{GHz})$ and $5.3 \mathrm{GHz}(5-5.6 \mathrm{GHz})$. During reverse bias of the diode $(-3 \mathrm{~V})$, the antenna resonated at $3.3 \mathrm{GHz}(2.8-$ $3.6 \mathrm{GHz})$ and $5.9 \mathrm{GHz}(5.5-6.1 \mathrm{GHz})$.

The measured resonant frequency at zero bias was $4.1 \mathrm{GHz}$ with a bandwidth of 3.7-4.9 GHz. During forward bias, the antenna resonated at $2.47 \mathrm{GHz}(2.2-2.6 \mathrm{GHz})$ and $5.4 \mathrm{GHz}$ (5.1-5.7 GHz). During reverse bias, the antenna resonated at $3.38 \mathrm{GHz}(2.8-3.7 \mathrm{GHz})$ and $6 \mathrm{GHz}(5.5-6.3 \mathrm{GHz})$. The small deviation between the measured and simulated results

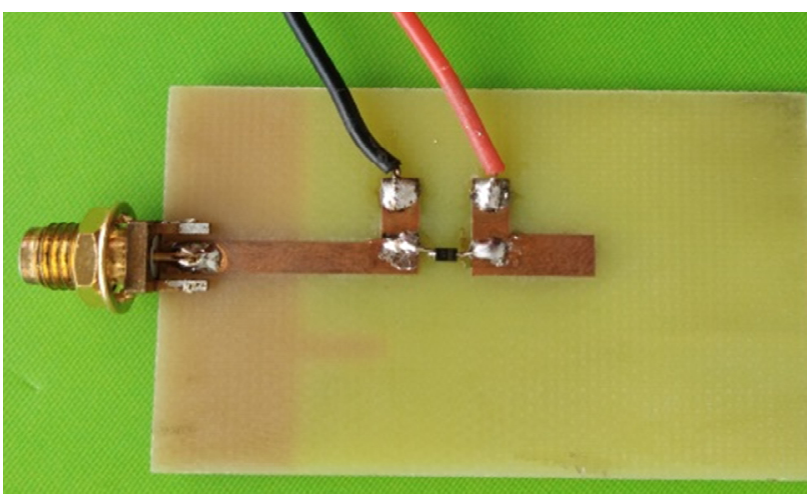

(a)

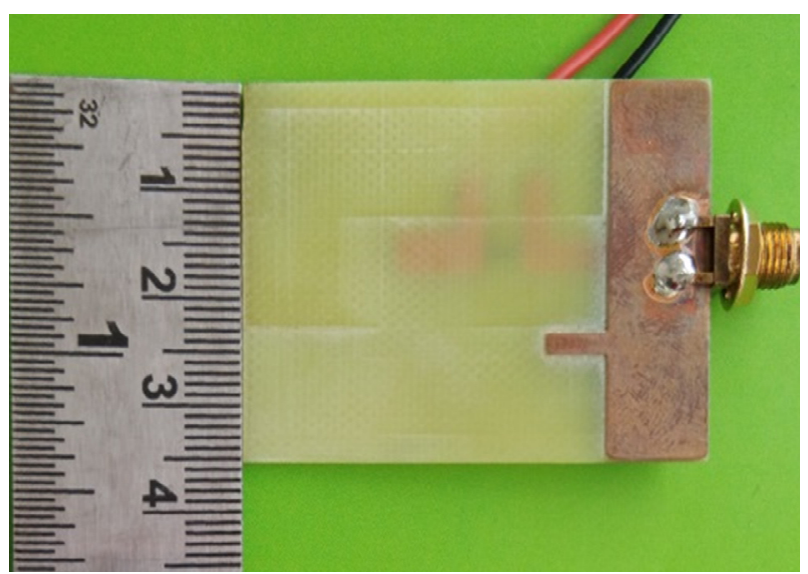

(b)

Fig. 6. A photograph of the fabricated antenna: (a) front view and (b) rear view.

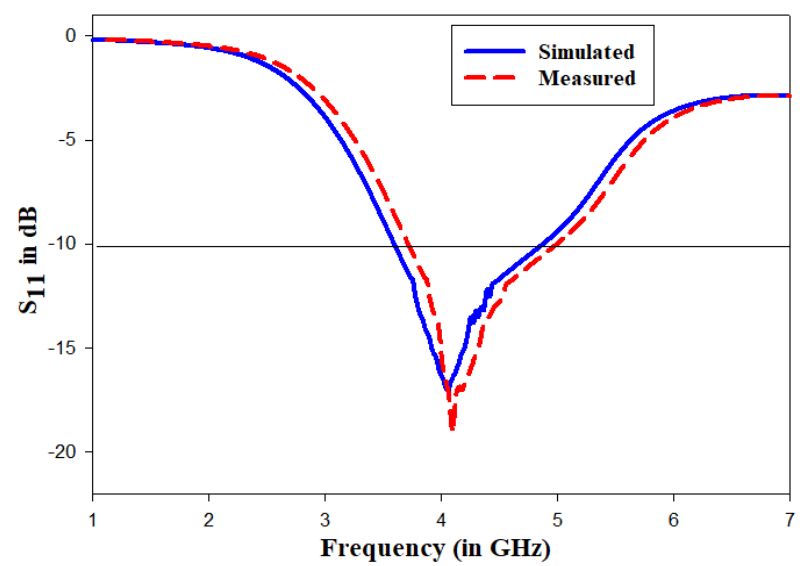

(a)

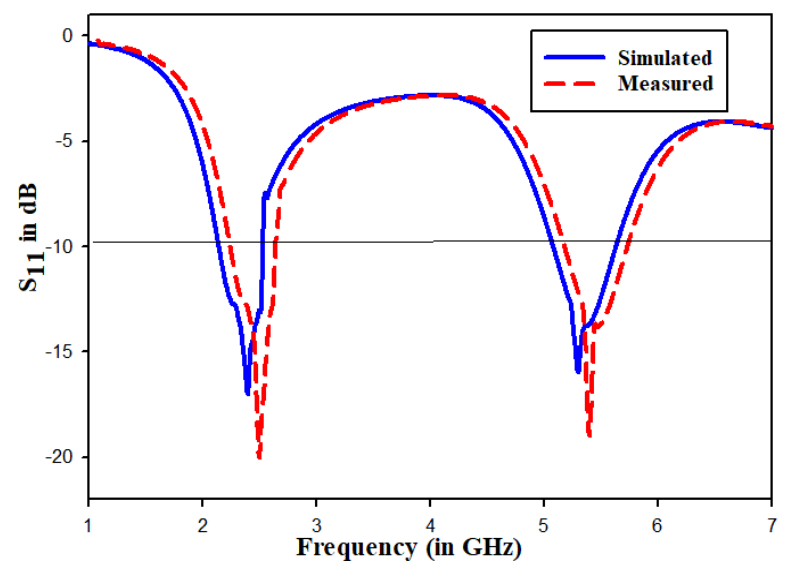

(b)

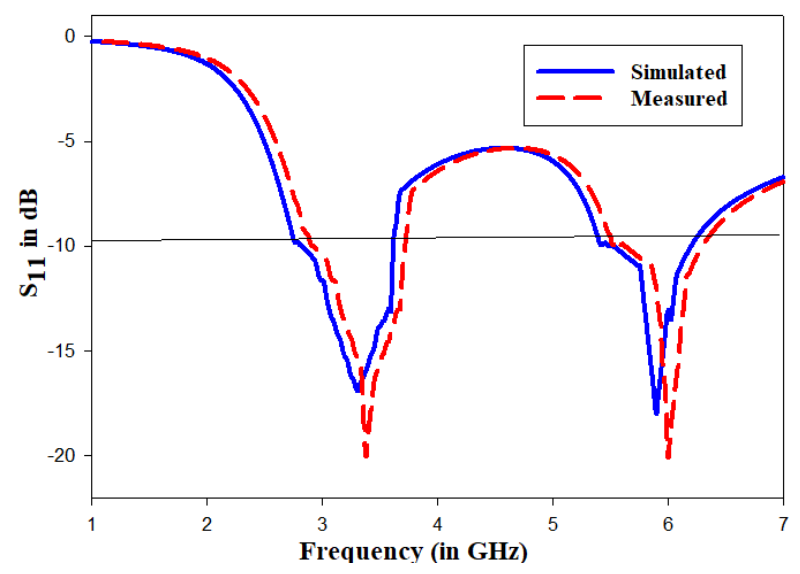

(c)

Fig. 7. Return loss at (a) zero bias, (b) forward bias, and (c) reverse bias.

could be due to minor fabrication errors and soldering losses in the SMA connector.

The measured gain at all resonant frequencies is displayed in Fig. 8. The gain varied between 2.6 and $5 \mathrm{dBi}$ for the operating frequencies, which is acceptable for the previously mentioned applications. The efficiencies of the proposed antenna at all biasing conditions are displayed in Fig. 9. Further, the maximum and minimum radiation efficiencies were $85 \%$ and $76 \%$, respectively. The simulated and measured $\mathrm{E}$ - and $\mathrm{H}$-plane gain patterns at all 


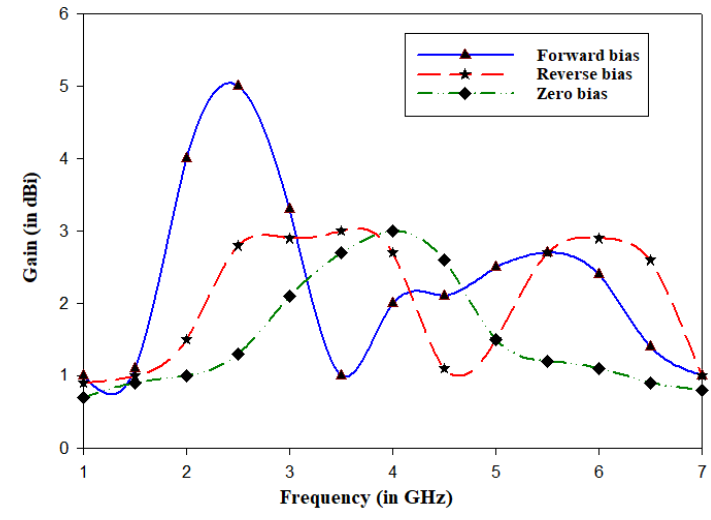

Fig. 8. Measured gain of proposed antenna.

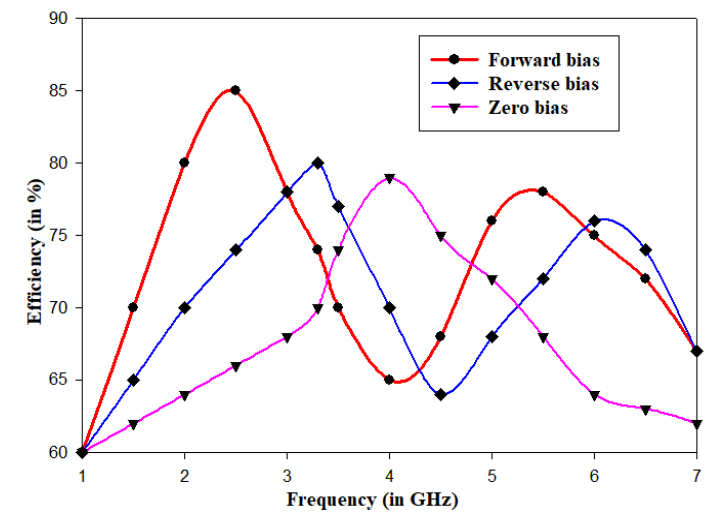

Fig. 9. Efficiency of proposed antenna. five operating frequencies are presented in Fig. 10. It can be observed that the antenna radiated omni-directionally in the $\mathrm{H}$ plane at 2.4,6, and $4.1 \mathrm{GHz}$. All the E-plane patterns adopted a figure-of- 8 shape, with a null lobe occurring at $90^{\circ}$. The simulated and measured patterns were in good agreement, with a minor difference of $0.5 \mathrm{~dB}$.

Table 3 presents a detailed summary of the simulated and measured results. Table 4 presents a detailed comparison between the proposed antenna and other (similar) models in the literature.

\section{CONCLUSION}

A simple and compact penta-band frequency-reconfigurable antenna is proposed in this paper. The presented patch antenna uses a single PIN diode connected between two rectangular strips. The various switching states of the PIN diode are responsible for achieving the desired operating frequency. It can operate at five frequency bands $(2.4,3.3,5.3,5.9$, and $4 \mathrm{GHz})$, rendering it suitable for applications in WLAN and 5G. The antenna has acceptable ranges of gain from 2.6 to $5 \mathrm{dBi}$, and the maximum efficiency is $85 \%$. This prototype was fabricated on easily available low-cost FR4 substrate, and the results were validated through measurements. The simulated results were in good agreement with the measured results.

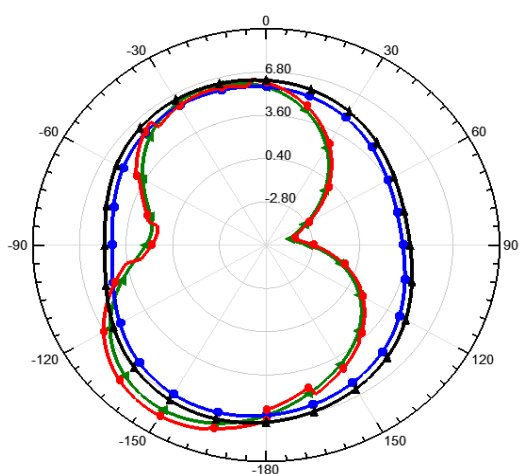

(a)

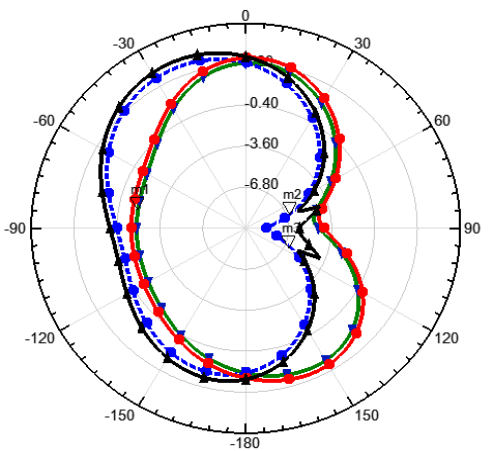

(d)

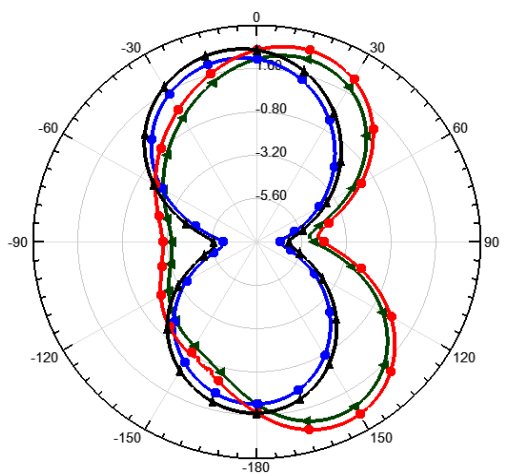

(b)

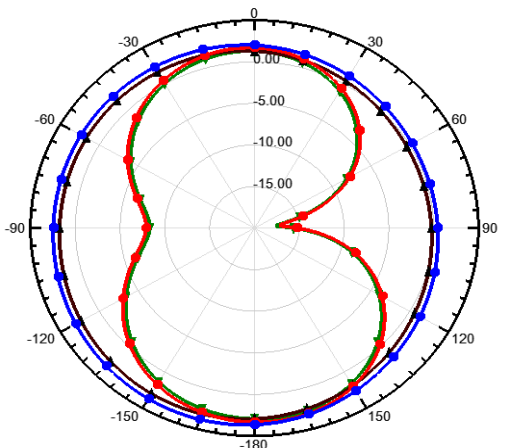

(e)

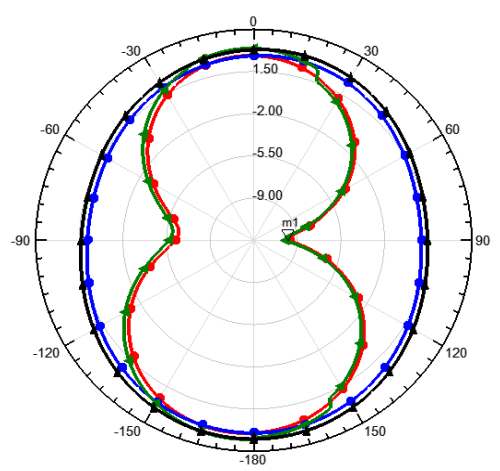

(c)

Fig. 10. Simulated and measured gains of E- and H-planes at (a) $2.4 \mathrm{GHz}$, (b) $5.4 \mathrm{GHz}$, (c) $3.3 \mathrm{GHz}$, (d) $6 \mathrm{GHz}$, and (e) $4.1 \mathrm{GHz}$. 
Table 3. Summary of simulated and measured results of the proposed antenna

\begin{tabular}{|c|c|c|c|c|c|c|c|c|c|c|}
\hline \multirow{3}{*}{$\begin{array}{c}\text { Parameter } \\
\text { Frequency }(\mathrm{GHz})\end{array}$} & \multicolumn{5}{|c|}{ Simulated results } & \multicolumn{5}{|c|}{ Measured results } \\
\hline & \multicolumn{2}{|c|}{ Forward bias } & \multicolumn{2}{|c|}{ Reverse bias } & \multirow{2}{*}{$\frac{\text { Zero bias }}{4}$} & \multicolumn{2}{|c|}{ Forward bias } & \multicolumn{2}{|c|}{ Reverse bias } & \multirow{2}{*}{$\begin{array}{c}\text { Zero bias } \\
4.1\end{array}$} \\
\hline & 2.4 & 5.3 & 3.3 & 5.9 & & 2.47 & 5.4 & 3.38 & 6 & \\
\hline Return loss (dB) & -16.8 & -15.6 & -16.7 & -17.7 & -16.4 & -19.8 & -18.6 & -19.8 & -19.6 & -18.5 \\
\hline Gain (dBi) & 4.5 & 2.4 & 2.8 & 2.4 & 2.7 & 5 & 2.7 & 3.1 & 2.6 & 3 \\
\hline Bandwidth $(\mathrm{GHz})$ & 0.4 & 0.6 & 0.8 & 0.6 & 1.1 & 0.4 & 0.6 & 0.9 & 0.8 & 1.2 \\
\hline Efficiency (\%) & 83 & 75 & 78 & 74 & 77 & 85 & 78 & 80 & 76 & 79 \\
\hline
\end{tabular}

Table 4. Performance comparison between proposed antenna and those in the literature

\begin{tabular}{ccccccc}
\hline Reference & Year & $\begin{array}{c}\text { Dimension } \\
(\mathrm{mm} \times \mathrm{mm})\end{array}$ & $\begin{array}{c}\text { Number of switches/diodes } \\
\text { and operating bands }\end{array}$ & $\begin{array}{c}\text { Frequency of } \\
\text { operation }(\mathrm{GHz})\end{array}$ & $\begin{array}{c}\text { Gain } \\
(\mathrm{dBi})\end{array}$ & Application \\
\hline$[17]$ & 2017 & $35 \times 53$ & 1, triple & $2.45,3.5,5.2$ & $1.7-3.4$ & Wi-Fi, WiMAX, WLAN \\
{$[18]$} & 2017 & $50 \times 50$ & 4, quad & $4.2,4.8,5.2,5.8$ & $3.2-4$ & Wireless communication service, \\
Telemetry, WLAN & WLAN \\
{$[19]$} & 2014 & $80 \times 45.8$ & 5, dual & $2.4,5.4$ & $2.6-5$ & Cognitive radio \\
{$[5]$} & 2020 & $60 \times 100$ & 2, dual & $0.430-1,1-5$ & 2.98 (max) & Wi-Fi, WLAN, WLAN \\
Proposed work & 2020 & $40 \times 35$ & 1, triple & $2.45,3.5,5.2$ & $1.48-3.26$ & WLAN, 5G \\
\hline
\end{tabular}

\section{REFERENCES}

[1] S. Rekha and M. Nesasudha, "Design of circularly polarized planar monopole antenna with improved axial ratio bandwidth," Microwave and Optical Technology Letters, vol. 59, no. 9, pp. 2353-2358, 2017.

[2] T. Ali and R. C. Biradar, "A compact hexagonal slot dual band frequency reconfigurable antenna for WLAN applications," Microwave and Optical Technology Letters, vol. 59, no. 4, pp. 958-964, 2017.

[3] H. Wong, W. Lin, L. Huitema, and E. Arnaud, "Multipolarization reconfigurable antenna for wireless biomedical system," IEEE Transactions on Biomedical Circuits and Systems, vol. 11, no. 3, pp. 652-660, 2017.

[4] W. Lin, H. Wong, and R. W. Ziolkowski, "Wideband pattern-reconfigurable antenna with switchable broadside and conical beams," IEEE Antennas and Wireless Propagation Letters, vol. 16, pp. 2638-2641, 2017.

[5] A. Kantemur, J. Tak, P. Siyari, A. H. Abdelrahman, M. Krunz, and H. Xin, "A novel compact reconfigurable broadband antenna for cognitive radio applications," IEEE Transactions on Antennas and Propagation, vol. 68, no. 9, pp. 65386547, 2020.

[6] R. K. Saraswat and M. Kumar, "A frequency band reconfig- urable UWB antenna for high gain applications," Progress in Electromagnetics Research B, vol. 64, pp. 29-45, 2015.

[7] M. N. M. Kehn, O. Quevedo-Teruel, and E. Rajo-Iglesias, "Reconfigurable loaded planar inverted-F antenna using varactor diodes," IEEE Antennas and Wireless Propagation Letters, vol. 10, pp. 466-468, 2011.

[8] G. Ruvio, M. J. Ammann, and Z. N. Chen, "Wideband reconfigurable rolled planar monopole antenna," IEEE Transactions on Antennas and Propagation, vol. 55, no. 6, pp. 1760$1767,2007$.

[9] S. A. A. Shah, M. F. Khan, S. Ullah, and J. A. Flint, "Design of a multi-band frequency reconfigurable planar monopole antenna using truncated ground plane for Wi-Fi, WLAN and WiMAX applications," in Proceedings of 2014 International Conference on Open Source Systems \& Technologies, Lahore, Pakistan, 2014, pp. 151-155.

[10] C. J. Panagamuwa, A. Chauraya, and J. C. Vardaxoglou, "Frequency and beam reconfigurable antenna using photoconducting switches," IEEE Transactions on Antennas and Propagation, vol. 54, no. 2, pp. 449-454, 2006.

[11] A. Boufrioua, "Frequency reconfigurable antenna designs using PIN diode for wireless communication applications," Wireless Personal Communications, vol. 110, no. 4, pp. 18791885, 2020. 
[12] M. J. Sathikbasha and V. Nagarajan, "Design of multiband frequency reconfigurable antenna with defected ground structure for wireless applications," Wireless Personal Communications, vol. 113, no. 2, pp. 867-892, 2020.

[13] T. Khan, M. Rahman, A. Akram, Y. Amin, and H. Tenhunen, "A low-cost CPW-fed multiband frequency reconfigurable antenna for wireless applications," Electronics, vol. 8, no. 8, article no. 900, 2019. https://doi.org/10. 3390/electronics 8080900

[14] I. A. Shah, S. Hayat, I. Khan, I. Alam, S. Ullah, and A. Afridi, "A compact, tri-band and 9-shape reconfigurable antenna for WiFi, WiMAX and WLAN applications," International Journal of Wireless and Microwave Technologies, vol. 6, no. 5, pp. 45-53, 2016.

[15] Y. P. Selvam, L. Elumalai, M. G. N. Alsath, M. Kanagasabai, S. Subbaraj, and S. Kingsly, "Novel frequency-and pattern-reconfigurable rhombic patch antenna with switchable polarization," IEEE Antennas and Wireless Propagation

\section{Rekha Shanmugam}

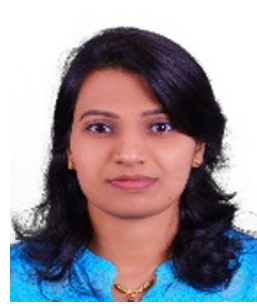

is currently working as an Assistant Professor in the Department of Electronics and Communication Engineering, Sreenidhi Institute of Science and Technology, Hyderabad, India. She received her $\mathrm{PhD}$ in the area of "Design and development of substrate integrated waveguide antennas" from Karunya Institute of Science and Technology, Coimbatore in 2019. She has 7 years of teaching and 5 years of Research experience. Her research areas include wireless sensor networks, antenna design (especially substrate integrated waveguide antennas), reconfigurable antennas, and MIMO antennas. She has more than 12 publications in internal conferences and journals, including Microwave and Optical technology letters (Wiley), International Journal of RF and Microwave computer Aided engineering (Wiley). She is a lifetime member of the CSI and a member of IEEE (Antenna and Propagation Society).
Letters, vol. 16, pp. 1639-1642, 2017.

[16] W. L. Stutzman and G. A. Thiele, Antenna Theory and Design. Hoboken, NJ: John Wiley \& Sons, 2013.

[17] S. Ullah, S. Hayat, A. Umar, U. Ali, F. A. Tahir, and J. A. Flint, "Design, fabrication and measurement of triple band frequency reconfigurable antennas for portable wireless communications," AEU-International Journal of Electronics and Communications, vol. 81, pp. 236-242, 2017.

[18] Y. P. Selvam, M. Kanagasabai, M. G. N. Alsath, S. Velan, S. Kingsly, S. Subbaraj, Y. V. R. Rao, R. Srinivasan, A. K. Varadhan, and M. Karuppiah, "A low-profile frequencyand pattern-reconfigurable antenna," IEEE Antennas and Wireless Propagation Letters, vol. 16, pp. 3047-3050, 2017.

[19] P. K. Li, Z. H. Shao, Q. Wang, and Y. J. Cheng, "Frequency-and pattern-reconfigurable antenna for multistandard wireless applications," IEEE Antennas and Wireless Propagation Letters, vol. 14, pp. 333-336, 2014. 